\title{
Dietary patterns and their association with obesity and sociodemographic factors in a national sample of Lebanese adults
}

\author{
Farah Naja ${ }^{1} \dagger$, Lara Nasreddine ${ }^{1} \dagger$, Leila Itani ${ }^{1}$, Marie Claire Chamieh ${ }^{1}$, Nada Adra ${ }^{\text {, }}$ \\ Abla Mehio Sibai ${ }^{2}$ and Nahla Hwalla ${ }^{1, *} \ddagger$ \\ 'Department of Nutrition and Food Sciences, Faculty of Agricultural and Food Sciences, American University of \\ Beirut, PO Box 11-0236, Riad El Solh, Beirut 1107-2020, Lebanon: ${ }^{2}$ Department of Epidemiology and \\ Population Health, American University of Beirut, Beirut, Lebanon
}

Submitted 29 June 2010: Accepted 25 February 2011: First published online 4 May 2011

\begin{abstract}
Objective: To identify and characterize dietary patterns in Lebanon and assess their association with sociodemographic factors, BMI and waist circumference (WC).

Design: A cross-sectional population-based survey. In a face-to-face interview, participants completed a brief sociodemographic and semiquantitative FFQ. In addition, anthropometric measurements were obtained following standard techniques. Dietary patterns were identified by factor analysis. Multivariate linear regression was used to assess determinants of the various patterns and their association with BMI and WC. Setting: National Nutrition and Non-Communicable Disease Risk Factor Survey (2009), Lebanon.

Subjects: A nationally representative sample of 2048 Lebanese adults aged 20-55 years. Results: Four dietary patterns were identified: 'Western', 'Traditional Lebanese', 'Prudent' and 'Fish and alcohol'. Factor scores of the identified patterns increased with age, except for the Western pattern in which a negative association was noted. Women had higher scores for the prudent pattern. Adults with higher levels of education had significantly higher scores for the prudent pattern. The frequency of breakfast consumption was significantly associated with scores of both traditional Lebanese and prudent patterns. Multivariate-adjusted analysis revealed a positive association between scores of the Western pattern and the BMI and WC of study participants.

Conclusions: The findings show the presence of four distinct dietary patterns in the Lebanese population, which were associated with age, sex, education and meal pattern. Only the Western pattern was associated with higher BMI.
\end{abstract}

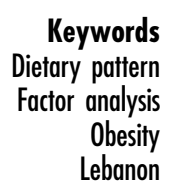

Diet is one important determinant in the development of several chronic diseases, which represent the leading causes of morbidity and mortality worldwide ${ }^{(1,2)}$. Traditional nutritional epidemiology investigating diet-disease associations has focused on a single food or a few foods and nutrients. This conventional approach has several limitations, mainly the interaction between nutrients, confounding by foods and nutrients not consumed and the problem of collinearity ${ }^{(3)}$. To overcome these limitations, nutritional epidemiologists have recently proposed studying dietary patterns as an alternative approach to evaluate diet-disease associations ${ }^{(4-6)}$. This approach looks beyond the single nutrient or food and attempts to capture the broader picture of diet that is hypothesized to discriminate

$\dagger$ F. Naja and L. Nasreddine contributed equally to this manuscript.

\$ All authors are members of the Public Health and Nutrition Research Group at the American University of Beirut, Lebanon. between health and disease ${ }^{(7)}$. Many studies have reported associations between dietary patterns and disease risks, including metabolic abnormalities, CVD and some cancers $^{(5,8-13)}$. Despite some inconsistencies, the results of these studies suggest that dietary patterns rich in whole grains, legumes, vegetables and fish are associated with favourable effects on metabolic abnormalities ${ }^{(14,15)}$, whereas Western dietary patterns, characterized by high-fat foods, increase the risk of obesity and metabolic abnormalities, such as type 2 diabetes and CVD ${ }^{(16-18)}$.

At the population level, as per WHO recommendations, all UN member states are urged to promote lifestyles that include a healthy diet and foster energy balance $^{(19)}$. In this context, the identification of the patterns of core staples around which diets are formed in a population is fundamental for planning and evaluating interventions on dietary intake. In fact, few recent interventional trials have shown that it is possible to modify 
underlying patterns in specific populations ${ }^{(20,21)}$. The public health message that comes from a dietary pattern approach is often clearer and easier to follow compared with recommendations that stem from individual foods and nutrients, especially given the inconsistent associations reported for most foods and nutrients ${ }^{(7)}$. In addition, knowledge of the determinants of specific food patterns is instrumental for the identification of groups at risk of under- or overconsumption of specific nutrients.

In the Middle East, limited data on dietary patterns, their determinants and disease associations exist. In the present paper, we report the following main outcomes from nationally representative and comprehensive dietary data in Lebanon: (i) identification and characterization of dietary patterns among Lebanese adults using factor analysis; (ii) investigation of the association of these patterns with sociodemographic factors, physical activity and meal patterns; and (iii) assessment of the association of these patterns with BMI and waist circumference (WC).

\section{Methods}

\section{Study design}

The data presented in the present paper are from a secondary analysis of the Nutrition and Non-Communicable Disease Risk Factor Survey conducted in Lebanon between 2008 and 2009 on a nationally representative sample of 3656 individuals aged $\geq 6$ years. The design and conduct of the survey are described in detail elsewhere (AM Sibai and $\mathrm{N}$ Hwalla, unpublished results). The present paper focused on 2048 adults aged $20-55$ years of both sexes. The sample was drawn from randomly selected households on the basis of stratified cluster sampling. The strata consisted of Lebanese governorates. The clusters were selected further at the level of districts and urban and rural areas; housing units constituted the primary sampling units in the different districts of Lebanon. One adult from each household was selected from the household roster, excluding pregnant and lactating women and individuals with mental disabilities. The distribution of the study sample by sex and 5-year age group was similar to that of the Lebanese population, as estimated by the Central Administration for Statistics in Lebanon $(2004)^{(22)}$. The present study was approved by the Institutional Review Board of the American University of Beirut.

Face-to-face interviews were conducted using a standard questionnaire that gathered information about basic sociodemographic (age, sex, marital status, education and income) and lifestyle characteristics (tobacco use and physical activity). The short version of the International Physical Activity Questionnaire was used to assess physical activity. Total physical activity was calculated by assigning a weight to each type of activity on the basis of its energy requirements defined in MET-min (multiples of the RMR for an activity multiplied by the minutes taken to perform it). Three categories of physical activity (low, moderate and high) were assigned on the basis of MET-min/week ${ }^{(23)}$. The interview schedule also included questions about meal patterns (breakfast consumption, snack consumption, eating out and eating while watching television (TV)).

\section{Antbropometric measurements}

Anthropometric measurements were taken using standardized techniques and calibrated equipment. Participants were weighed to the nearest $0 \cdot 1 \mathrm{~kg}$ wearing light indoor clothing, and were barefoot or wearing stockings. Using a stadiometer, height was measured without shoes and recorded to the nearest $0.5 \mathrm{~cm}$. BMI was calculated as weight in kilograms divided by the square of height in metres $\left(\mathrm{kg} / \mathrm{m}^{2}\right)$. WC was measured using a plastic measuring tape to the nearest $0.5 \mathrm{~cm}$ at the midpoint between the bottom of the rib cage and above the top of the iliac crest during minimal respiration.

\section{Assessment of dietary intake}

Dietary intake was assessed by a sixty-one-item FFQ that estimated food and beverage intakes over the past year. The questionnaire was administered by a trained dietitian who collected information on consumption of commonly consumed food items and beverages in Lebanon. Participants had the choice to report their intake either in terms of reference portion size or in grams. A reference portion, representing one standard serving expressed in household measures, was defined for each food item. Common household measures such as measuring cups, spoons and portion size photos were used for better estimation of the real portion consumed. The reported frequency of each food item and beverage was then converted to a daily portion intake. The daily energy and macronutrient consumption by participants was computed using the food composition database of the Nutritionist IV software (N-Squared Computing, Silverton, OR, USA).

Both the FFQ and the above-mentioned sociodemographic questionnaire were designed by a panel of experts including scientists in the fields of epidemiology and nutrition and were tested on a convenient sample to check for clarity and cultural sensitivity.

\section{Determination of dietary patterns}

For the purpose of determination of dietary patterns, food items were grouped into thirty food groups on the basis of similarities in ingredients, nutrient profile and/or culinary usage (Appendix). Food items having a unique composition (eggs, burghul (parboiled wheat) and mayonnaise) were classified individually. The total consumption for each group was determined by summing up the daily portion intake of each item in this group. The exploratory principal component factor analysis (PCFA) was used to identify dietary patterns using intakes of the thirty food groups. PCFA is a data-driven method that identifies foods that are frequently consumed together by pooling food items on the basis of the degree to which 
the amounts eaten are correlated together. Its main purpose is to identify groups of food items that account for the largest variation in overall dietary intake among individuals ${ }^{(24)}$. Before running the factor analysis procedure, the correlation matrix among the thirty food groups was visually and statistically examined to justify undertaking factor analysis. The $\chi^{2}$ for the Bartlett test of sphericity was significant at $P<0.05$, and the Kaiser-Meyer-Olkin test showed a score of $>0 \cdot 6$, indicating that the correlation among the variables was sufficiently strong for a factor analysis. The number of factors retained was based on three criteria: (i) the Kaiser criterion (eigenvalues $>1$ ); (ii) inflection point of the scree plot; and (iii) interpretability of factors. The factors were rotated using a Varimax rotation (orthogonal transformation). Factor loadings indicated the strength and direction of the association between the patterns and food groups. The derived dietary patterns were labelled on the basis of food groups having a rotated factor loading $>0 \cdot 4$. Factor scores were calculated using the multiple regression approach and each individual received a factor score for each dietary pattern. These scores indicated the degree to which each participant's diet corresponded to the identified pattern. For each pattern, participants were grouped into quartiles of pattern scores.

\section{Statistical analyses}

To study the association between dietary patterns and nutrient intake, Pearson's correlation coefficients were calculated between the factor scores of each pattern and energy-adjusted nutrient intakes. Multiple linear regression analysis was applied to assess the associations of the dietary patterns, with factor scores of each of the identified patterns as the dependent variable and the sociodemographic characteristics and meal pattern as independent variables. The associations between BMI, WC and dietary patterns were evaluated using multivariate linear regression adjusted for age, sex, education, income, smoking, physical activity and energy intake. Tests were conducted to determine linearity (tolerance $>0.4$ ) of the covariates included in the regression models. Normality of the residuals was assessed by the histogram of standardized residuals and normal probability plot in all regression models. The Statistical Package for the Social Sciences statistical software package version $14 \cdot 1$ (SPSS Inc., Chicago, IL, USA) was used for all computations, and a $P$ value $<0 \cdot 05$ was considered significant.

\section{Results}

Out of 3178 visited households, 2836 agreed to participate in the study (response rate $90 \%$ ). No information existed on individuals who refused to participate. Our sample comprised 2048 adult participants aged 20-55 years (923 men with a mean age of 34.7 (SD 9.9) years and 1125 women with a mean age of 34.8 (SD 9.9) years). A significantly higher percentage of men were single, had a higher income and smoked cigarettes. Overall, almost half of the study population had a low level of physical activity $(48 \cdot 1 \%)$. The frequency of breakfast consumption was about 5 times/ week for both men and women. A greater percentage of men reported eating out and eating while watching TV. The prevalence of obesity $\left(\mathrm{BMI} \geq 30 \cdot 0 \mathrm{~kg} / \mathrm{m}^{2}\right)$ and elevated WC ( $\geq 94 \mathrm{~cm}$ for men and $\geq 80 \mathrm{~cm}$ for women, according to the International Diabetes Foundation cut-offs) was significantly greater among men as compared with women (Table 1).

Principal component analysis revealed four dietary patterns, which collectively explained $27 \cdot 6 \%$ of the variance in dietary intake. Factor loadings of the four patterns are shown in Table 2 . The patterns were named according to the food groups loading highest on the respective dietary pattern. Therefore, the patterns obtained were classified as follows: (i) the 'Western' pattern, which was positively associated with fast food including pies and pizzas, fastfood sandwiches, fried potatoes, regular soda, bottled juices, meat and poultry, cured meats, nuts and seeds, refined grains, mayonnaise, ice cream and sweets; (ii) the 'Traditional Lebanese', which was positively associated with traditional Lebanese food such as fruit, vegetables, burghul, legumes, olives, whole-fat dairy, starchy vegetables, fats and oils, and eggs; (iii) the 'Prudent' pattern, which was positively associated with food recognized as healthy, including primarily whole bread, low-fat dairy and light soda and negatively associated with refined grains, fats and oils and regular soda; and (iv) the 'Fish and alcohol' pattern, which was associated with consumption of fish and alcohol.

Table 3 describes the associations of the factor scores of various dietary patterns with energy and energy-adjusted nutrient intakes. Scores of the Western pattern had the strongest positive associations with energy $(r=0 \cdot 78)$, fat $(r=0 \cdot 11)$ and $\mathrm{Na}(r=0 \cdot 16)$ intakes. The traditional pattern scores were positively correlated with carbohydrates $(r=0.07)$ and cholesterol $(r=0.9)$ intakes. As for the prudent pattern, the higher the scores, the lower the energy $(r=-0 \cdot 26)$ and $\mathrm{Na}(r=-0 \cdot 21)$ intakes and the higher the fibre intake $(r=0 \cdot 42)$. The fish and alcohol pattern was characterized by a high intake of protein $(r=0 \cdot 28)$ and low intake of carbohydrates $(r=-0 \cdot 32)$.

Multiple linear regression models were applied to examine the independent associations of selected sociodemographic and lifestyle characteristics with the scores of the four dietary patterns identified in the present study. When examined, gender was not shown to be an effect modifier of the association between the various patterns and BMI and WC; hence, the results for both genders together are presented in Tables 4 and 5. Table 4 represents the regression coefficients and the corresponding $P$ values of the aforementioned models. In particular, the Western pattern was positively associated with male sex, frequency of eating out, snacking and high socio-economic status, whereas it was negatively associated with age and education. The traditional Lebanese pattern was positively associated with age, breakfast consumption, snacking and higher economic 
Table 1 Sociodemographic, lifestyle and anthropometric characteristics of the study populationt: nationally representative sample of Lebanese adults ( $n$ 2048) aged 20-55 years

\begin{tabular}{|c|c|c|c|c|c|c|c|}
\hline & \multicolumn{2}{|c|}{ Total ( $n$ 2048) } & \multicolumn{2}{|c|}{ Men ( $n$ 923) } & \multicolumn{2}{|c|}{ Women (n 1125) } & \multirow[b]{2}{*}{ Significanceł } \\
\hline & Mean or $n$ & SD or $\%$ & Mean or $n$ & SD or $\%$ & Mean or $n$ & SD or $\%$ & \\
\hline Age (years) & $34 \cdot 7$ & $9 \cdot 9$ & $34 \cdot 5$ & $10 \cdot 0$ & $34 \cdot 8$ & $9 \cdot 9$ & $P>0.05$ \\
\hline \multicolumn{8}{|l|}{ Income per month (million LL)§ } \\
\hline$<1$ & 1447 & $70 \cdot 8$ & 603 & $65 \cdot 5$ & 844 & $75 \cdot 2$ & \\
\hline $1<$ Income $<3$ & 501 & $24 \cdot 5$ & 264 & $28 \cdot 7$ & 237 & $21 \cdot 1$ & \\
\hline$>3$ & 96 & $4 \cdot 7$ & 54 & $5 \cdot 9$ & 42 & $3 \cdot 7$ & $\chi^{2}=23.36 ; P<0.001$ \\
\hline \multicolumn{8}{|l|}{ Marital status } \\
\hline Single & 861 & $42 \cdot 1$ & 462 & $50 \cdot 1$ & 399 & $35 \cdot 5$ & \\
\hline Married & 1185 & $57 \cdot 9$ & 460 & $49 \cdot 9$ & 725 & $64 \cdot 5$ & $\chi^{2}=44.4 ; P<0.001$ \\
\hline \multicolumn{8}{|l|}{ Educational level } \\
\hline Illiterate, primary education & 269 & $13 \cdot 1$ & 130 & $14 \cdot 1$ & 139 & $12 \cdot 4$ & \\
\hline Elementary & 514 & $25 \cdot 1$ & 243 & $26 \cdot 3$ & 271 & $24 \cdot 1$ & \\
\hline Secondary & 346 & $16 \cdot 9$ & 143 & $15 \cdot 5$ & 203 & $18 \cdot 0$ & \\
\hline Technical & 221 & $10 \cdot 8$ & 107 & $11 \cdot 6$ & 114 & $10 \cdot 1$ & \\
\hline University and higher education & 698 & $34 \cdot 1$ & 300 & $32 \cdot 5$ & 398 & $35 \cdot 4$ & $\chi^{2}=6.35 ; P>0.05$ \\
\hline \multicolumn{8}{|l|}{ Family history of obesity } \\
\hline No & 1131 & $55 \cdot 5$ & 556 & $60 \cdot 6$ & 575 & $51 \cdot 3$ & \\
\hline Yes & 907 & $44 \cdot 5$ & 362 & $39 \cdot 4$ & 545 & $48 \cdot 7$ & $\chi^{2}=17.39 ; P<0.001$ \\
\hline \multicolumn{8}{|l|}{ Smoking\| } \\
\hline No & 1267 & $61 \cdot 9$ & 467 & $50 \cdot 6$ & 800 & $71 \cdot 1$ & \\
\hline Yes & 781 & $38 \cdot 1$ & 456 & $49 \cdot 4$ & 325 & $28 \cdot 9$ & $\chi^{2}=90.45 ; P<0.001$ \\
\hline \multicolumn{8}{|l|}{ Physical activity level } \\
\hline Low & 841 & $48 \cdot 1$ & 434 & $53 \cdot 3$ & 407 & $43 \cdot 6$ & \\
\hline Moderate & 485 & $27 \cdot 7$ & 211 & $25 \cdot 9$ & 274 & $29 \cdot 4$ & \\
\hline High & 422 & $24 \cdot 1$ & 170 & $20 \cdot 9$ & 252 & $27 \cdot 0$ & $\chi^{2}=17 \cdot 1 ; P<0.001$ \\
\hline Breakfast per week & $4 \cdot 7$ & $2 \cdot 9$ & $4 \cdot 8$ & $2 \cdot 9$ & $4 \cdot 6$ & $2 \cdot 9$ & $P>0.05$ \\
\hline Snack per day & $1 \cdot 5$ & $1 \cdot 3$ & $1 \cdot 5$ & $1 \cdot 4$ & 1.5 & $1 \cdot 1$ & $P>0.05$ \\
\hline Eating while watching TV per week & $3 \cdot 1$ & $3 \cdot 2$ & $3 \cdot 5$ & $3 \cdot 2$ & $2 \cdot 8$ & $3 \cdot 1$ & $P<0.001$ \\
\hline Eating out per week & $1 \cdot 6$ & $2 \cdot 2$ & $2 \cdot 4$ & $2 \cdot 5$ & $1 \cdot 0$ & $1 \cdot 5$ & $P<0.001$ \\
\hline BMI $\left(\mathrm{kg} / \mathrm{m}^{2}\right)$ & $26 \cdot 6$ & $5 \cdot 3$ & $27 \cdot 3$ & $4 \cdot 9$ & $26 \cdot 0$ & $5 \cdot 6$ & $P<0.001$ \\
\hline Overweight $(\mathrm{BMI} \geq 25)$ & 1154 & $57 \cdot 1$ & 608 & $66 \cdot 6$ & 546 & $49 \cdot 3$ & $\chi^{2}=61.27 ; P<0.001$ \\
\hline Obese $(\mathrm{BMI} \geq 30)$ & 867 & $22 \cdot 4$ & 226 & $24 \cdot 6$ & 227 & $20 \cdot 5$ & $\chi^{2}=5.04 ; P<0.05$ \\
\hline WC $(\mathrm{cm})$ & $87 \cdot 82$ & $14 \cdot 15$ & $93 \cdot 4$ & $13 \cdot 3$ & $83 \cdot 3$ & $13 \cdot 1$ & $P<0.001$ \\
\hline Elevated WC & 1001 & $49 \cdot 1$ & 489 & $53 \cdot 4$ & 512 & $45 \cdot 7$ & $\chi^{2}=11.99 ; P<0.001$ \\
\hline
\end{tabular}

LL, Lebanese Liras; TV, television; WC, waist circumference.

tCategorical variables are expressed as $n$ and \% and continuous variables are expressed as mean and SD.

$\ddagger$ Significance is derived using an independent $t$ test for continuous variables and the $\chi^{2}$ test for categorical variables.

\$lncome is expressed in terms of LL (1500 LL is almost equivalent to \$US 1).

॥Smokers were defined as current smokers, whereas non-smokers included non-smokers and past smokers.

- Elevated WC is defined by a circumference $\geq 94 \mathrm{~cm}$ for men and $\geq 80 \mathrm{~cm}$ for women according to the International Diabetes Federation.

status and negatively associated with the frequency of eating out. In addition, this pattern showed a significant positive association with physical activity. The prudent pattern was positively associated with female sex, breakfast consumption and education and negatively associated with marital status and eating while watching TV. The fish and alcohol pattern was positively associated with age, income and the frequency of eating out and negatively associated with female sex, eating while watching TV and breakfast consumption. Table 5 illustrates the multivariate-adjusted association of the four dietary patterns identified with BMI and WC of study participants. Scores of the Western pattern were significantly positively associated with BMI and WC (BMI: $\beta=0 \cdot 49,95 \%$ CI $0 \cdot 21,0 \cdot 76$; WC: $\beta=1 \cdot 08,95 \%$ CI $0 \cdot 39,1 \cdot 76$ ).

\section{Discussion}

In the present study, we report the results of the first national investigation of dietary patterns among Lebanese adults and their association with obesity, sociodemographic factors and lifestyle variables. Four major dietary patterns were identified in this population. The Western pattern was characterized mainly by a high consumption of fried potatoes, pizzas and pies, soda drinks, fast-food sandwiches and sweets. The traditional Lebanese pattern reflected high intakes of fruit, vegetables, legumes and olives. The prudent pattern consisted mainly of low-fat dairy, whole bread, breakfast cereals and light soda. The fish and alcohol pattern was, as its name depicts, characterized by a high consumption of fish and alcohol. Among the four dietary patterns identified, only the Western pattern was positively associated with BMI and WC. The percentage of variance of dietary intake explained by the aforementioned patterns was $27 \cdot 64 \%$, with the largest variance being explained by the Western pattern (10\%). The percentage of variance explained by the first four dietary patterns identified is similar in magnitude to what has been reported in other studies ${ }^{(25-27)}$. It should be noted, however, that the variance explained by all factors is a function of the number of factors that researchers choose to retain ${ }^{(28)}$. 
Table 2 Factor loading matrix for the four dietary patterns identified in the study population

\begin{tabular}{|c|c|c|c|c|}
\hline \multirow[b]{2}{*}{ Food group } & \multicolumn{4}{|c|}{ Dietary pattern } \\
\hline & Western & Traditional Lebanese & Prudent & Fish and alcohol \\
\hline Fried potato & 0.64 & & & \\
\hline Pizzas and pies & 0.61 & & & \\
\hline Regular soda & 0.58 & & -0.20 & \\
\hline Fast-food sandwiches & 0.50 & & & \\
\hline Mayonnaise & 0.50 & & & \\
\hline Sweets & 0.48 & $0 \cdot 24$ & & -0.39 \\
\hline Cured meat & 0.48 & & & \\
\hline Nuts and seeds & 0.36 & & & $0 \cdot 23$ \\
\hline Meat and poultry & 0.33 & & & 0.22 \\
\hline Bottled fruit juices & $0 \cdot 31$ & $0 \cdot 21$ & & \\
\hline Ice cream & $0 \cdot 31$ & & & \\
\hline Fruit & & 0.60 & & \\
\hline Vegetables & & 0.58 & & $0 \cdot 21$ \\
\hline Legumes & & 0.49 & & \\
\hline Olives & & 0.40 & $-0 \cdot 30$ & \\
\hline Burghul (crushed wheat) & & $0 \cdot 39$ & & \\
\hline Whole-dairy products & $0 \cdot 22$ & $0 \cdot 37$ & & \\
\hline Starchy vegetables & & 0.35 & 0.22 & \\
\hline Eggs & & $0 \cdot 27$ & & \\
\hline Dried fruits & & $0 \cdot 24$ & & \\
\hline Refined grains & 0.40 & & -0.58 & \\
\hline Whole bread & & & 0.43 & \\
\hline Low-fat dairy products & & & 0.42 & \\
\hline Turkish coffee & & & -0.40 & $0 \cdot 40$ \\
\hline Breakfast cereals & & & 0.39 & \\
\hline Fats and oils & $0 \cdot 21$ & $0 \cdot 31$ & -0.34 & \\
\hline Light soda & & & $0 \cdot 33$ & $0 \cdot 28$ \\
\hline Alcoholic beverages & & & & 0.58 \\
\hline Hot drinks & & $0 \cdot 25$ & $0 \cdot 27$ & -0.47 \\
\hline Fish & & $0 \cdot 32$ & & 0.45 \\
\hline Percentage variance explained by each pattern & $9 \cdot 92$ & $7 \cdot 24$ & $5 \cdot 63$ & $4 \cdot 84$ \\
\hline
\end{tabular}

Total variance explained by all of the patterns is $27 \cdot 64 \%$.

Absolute values $<0.2$ were excluded from the table for simplicity. Loadings $\geq 0.4$ are given in bold.

Table 3 Pearson's correlation coefficients of dietary pattern scores with total energy and energy-adjusted nutrient intakest

\begin{tabular}{|c|c|c|c|c|}
\hline & \multicolumn{4}{|c|}{ Dietary pattern } \\
\hline & Western & Lebanese & Prudent & Fish and alcohol \\
\hline Energył & $0.783^{\star \star}$ & $0.430^{* *}$ & $-0.262^{\star \star}$ & $0 \cdot 115^{\star *}$ \\
\hline Protein $(\mathrm{g})$ & $-0 \cdot 175^{\star \star}$ & $0.089^{\star *}$ & $0.382^{\star *}$ & $0 \cdot 283^{\star *}$ \\
\hline Carbohydrate $(\mathrm{g})$ & $-0.083^{\star \star}$ & $0.069^{\star \star}$ & $-0 \cdot 155^{\star \star}$ & $-0 \cdot 320^{\star *}$ \\
\hline Fat (g) & $0 \cdot 108^{\star \star}$ & $-0.064^{\star *}$ & $0.054^{*}$ & 0.038 \\
\hline Fibre $(\mathrm{g})$ & $-0.415^{\star \star}$ & $0.311^{\star *}$ & $0.415^{\star *}$ & $0 \cdot 104^{\star *}$ \\
\hline Cholesterol (mg) & 0.038 & $0.085^{\star \star}$ & 0.020 & 0.023 \\
\hline $\mathrm{Na}(\mathrm{mg})$ & $0 \cdot 156^{\star \star}$ & -0.037 & $-0 \cdot 208^{\star *}$ & 0.024 \\
\hline $\mathrm{Ca}(\mathrm{mg})$ & $-0 \cdot 196^{\star *}$ & $0.096^{\star *}$ & $0.326^{\star \star}$ & $-0.073^{\star *}$ \\
\hline
\end{tabular}

Correlation is significant at ${ }^{\star} P<0.05$ and ${ }^{\star \star} P<0.01$.

tAdjustment for energy was carried out as percentage of total energy intake for protein, carbohydrates and fat and as $\mathrm{g}$ or $\mathrm{mg}$ intake per $\mathrm{kcal} / \mathrm{d}$ for all other nutrients.

$\ddagger$ Absolute values for the correlation of total energy intake with dietary pattern scores are indicated.

Although the specific foods contributing to each pattern may vary in their level of contribution, the prudent and Western patterns are the most commonly identified dietary patterns among adults from the USA and Western Europe, where the Western pattern is generally defined as a high-fat diet with red and processed meat, high-fat dairy products and refined cereals, and the prudent or healthy pattern is often marked by consumption of fruit and vegetables, whole grains and fish ${ }^{(29)}$. The prudent pattern in the present study, although including low-fat dairy and whole bread, is slightly different from what has been reported in the literature, because fruit, vegetables and fish are loaded on other patterns. In addition to the fact that fruits and vegetables are essential elements of the Lebanese diet, as will be discussed later, these differences stem from the fact that factor analysis is a data-driven method and differences in the dietary assessment methods, the number and types of food groupings and statistical analysis techniques may explain the observed discrepancies in what constitutes a prudent dietary pattern across the literature ${ }^{(30)}$. As the use of dietary pattern analysis is becoming more widespread, additional patterns have been identified for ethnic or countryspecific traditional diets, such as the 'bean pattern' among women of Chinese or Japanese ancestry ${ }^{(31)}$, the traditional Korean pattern ${ }^{(32)}$ and the traditional Iranian pattern $^{(33,34)}$. In our study, in addition to the Western and prudent patterns, we have identified the traditional Lebanese pattern, which shared elements with what are generally labelled as Western and prudent patterns, since 
Table 4 Association of baseline sociodemographic and lifestyle characteristics with various pattern scores in the study population as assessed by multivariate linear regressiont

\begin{tabular}{|c|c|c|c|c|c|c|c|c|}
\hline \multirow[b]{2}{*}{ Sociodemographic characteristic } & \multicolumn{2}{|r|}{ Western } & \multicolumn{2}{|c|}{ Traditional Lebanese } & \multicolumn{2}{|r|}{ Prudent } & \multicolumn{2}{|c|}{ Fish and alcohol } \\
\hline & $\beta$ & $95 \% \mathrm{Cl}$ & $\beta$ & $95 \% \mathrm{Cl}$ & $\beta$ & $95 \% \mathrm{Cl}$ & $\beta$ & $95 \% \mathrm{Cl}$ \\
\hline Cons & 0. & $0.366,1$ & $33^{*}$ & $-0.983,-0.183$ & $-1 \cdot 027$ & $-1.439,-0.615$ & $-0 \cdot 686^{\star}$ & $-1 \cdot 071,-0.301$ \\
\hline Age & $-0 \cdot 023^{\star}$ & $-0.028,-0.018$ & $0 \cdot 015^{*}$ & $0.009,0.020$ & $0.009^{*}$ & $0.003,0.015$ & $0 \cdot 016^{\star}$ & $0.011,0.021$ \\
\hline Sex & $-0 \cdot 385^{\star}$ & $-0.473,-0.296$ & $-0 \cdot 388^{*}$ & $-0.482,-0.294$ & $0 \cdot 345^{\star}$ & $0 \cdot 247,0.442$ & $-0 \cdot 223^{*}$ & $-0.314,-0.132$ \\
\hline Education & -0.025 & $-0.056,0.006$ & 0.032 & $-0.001,0.064$ & $0 \cdot 197^{*}$ & $0 \cdot 163,0.230$ & $0 \cdot 041^{*}$ & $0.009,0.072$ \\
\hline Income & $0 \cdot 113^{\star}$ & $0.042,0.184$ & $0.099^{*}$ & $0.023,0.175$ & $-0.082^{*}$ & $-0.160,-0.003$ & 0.026 & $-0.047,0.099$ \\
\hline Marital status & -0.037 & $-0.137,0.063$ & 0.056 & $-0.051,0.162$ & $-0 \cdot 156^{\star}$ & $-0.265,-0.046$ & -0.015 & $-0.117,0.088$ \\
\hline Smoking & 0.028 & $-0.063,0.119$ & $-0 \cdot 104^{*}$ & $-0.200,-0.007$ & $-0 \cdot 188^{*}$ & $-0.288,-0.089$ & $0 \cdot 305^{\star}$ & $0.212,0.398$ \\
\hline Physical activity & $0 \cdot 028$ & $-0.022,0.078$ & $0 \cdot 103^{\star}$ & $0 \cdot 050,0 \cdot 157$ & 0.013 & $-0.042,0.068$ & 0.043 & $-0.009,0.094$ \\
\hline Family history of obesity & -0.002 & $-0.084,0.079$ & -0.034 & $-0.120,0.053$ & -0.017 & $-0.106,0.073$ & $0 \cdot 014$ & $-0.069,0.098$ \\
\hline Breakfast consumption per week & 0.003 & $-0.012,0.017$ & $0 \cdot 036^{*}$ & $0.021,0.052$ & $0 \cdot 018^{*}$ & $0.002,0.034$ & $-0.044^{\star}$ & $-0.058,-0.029$ \\
\hline Snack consumption per day & $0 \cdot 163^{\star}$ & $0 \cdot 130,0 \cdot 196$ & $0 \cdot 141^{*}$ & $0 \cdot 107,0 \cdot 176$ & 0.034 & $-0.002,0.070$ & -0.014 & $-0.047,0.02$ \\
\hline Eating while watching TV per week & $0 \cdot 034^{\star}$ & $0.021,0.046$ & -0.003 & $-0.017,0.011$ & $-0 \cdot 020^{*}$ & $-0.034,-0.006$ & $-0 \cdot 019^{\star}$ & $-0.032,-0.005$ \\
\hline Frequency of eating out per week & $0 \cdot 103^{\star}$ & $0.082,0.124$ & $-0.041^{*}$ & $-0.064,-0.01$ & $0.055^{\star}$ & $0.032,0.078$ & $0 \cdot 048^{\star}$ & $0.027,0.07$ \\
\hline
\end{tabular}

TV, television.

${ }^{*} \beta$ and $95 \% \mathrm{Cl}$ are significant at $P<0.05$.

tAll the sociodemographic and lifestyle variables were run in one multivariate model.

Table 5 Association of BMI and WC of study participants with the scores of the four dietary patterns identified as assessed by multivariate linear regressiont

\begin{tabular}{lccccr}
\hline & \multicolumn{2}{c}{$\mathrm{BMI}\left(\mathrm{kg} / \mathrm{m}^{2}\right)$} & & \multicolumn{2}{c}{$\mathrm{WC}(\mathrm{cm})$} \\
\cline { 2 - 3 } \cline { 5 - 6 } Pattern & $\beta$ & $95 \% \mathrm{Cl}$ & & $\beta$ & $95 \% \mathrm{Cl}$ \\
\hline Western & $0.49^{*}$ & $0.21,0.76$ & & $1.08^{*}$ & $0.39,1.76$ \\
Traditional Lebanese & 0.14 & $-0.12,0.40$ & & 0.40 & $-0.25,1.05$ \\
Prudent & 0.23 & $-0.02,0.48$ & & 0.59 & $-0.03,1.21$ \\
Fish and alcohol & 0.24 & $-0.02,0.50$ & & 0.39 & $-0.27,1.04$ \\
\hline
\end{tabular}

WC, waist circumference.

${ }^{*} \beta$ and $95 \% \mathrm{Cl}$ are significant at $P<0.05$.

tThe multivariate regression model was adjusted for age, sex, education, income, smoking, physical activity and energy intake.

it included fruit and vegetables and whole-dairy products in addition to olives and burghul (crushed wheat). The fourth pattern identified in the present study, the fish and alcohol pattern, is specific to the Lebanese population, although few other studies have identified patterns driven by alcohol ${ }^{(11)}$.

A main criticism of dietary pattern analysis is the labelling of factors, which is arbitrary and based on the investigator's interpretation of the factors. In her recent review, Slattery ${ }^{(35)}$ stressed on the importance of understanding what is behind the label. The correlation of the patterns' scores with energy and energy-adjusted nutrients in the present study further characterized the factors and explained the labelling. Similar to the majority of studies that have investigated dietary patterns, the pattern associated with higher energy consumption, fat, saturated fat and $\mathrm{Na}$ and lower fibre intakes was depicted as the Western pattern, whereas the prudent pattern was the factor that correlated with higher fibre and $\mathrm{Ca}$ intakes ${ }^{(29)}$.

We found that the factor scores were associated with several demographic factors, including age, sex and education. Similar to other studies, our results showed that younger individuals followed the Western pattern ${ }^{(36-38)}$. This finding is alarming from the point of view of population health given the reported relationship between Western dietary patterns and adverse health outcomes ${ }^{(5,8-10,39)}$. The observed differences in eating patterns by gender are in accordance with those reported by other investigators ${ }^{(40,41)}$, where women seemed to adhere more to the prudent pattern, whereas men were found to follow mainly the Western pattern. Similar to other reports in the literature, adherence to the prudent pattern was found to be positively associated with education. This was also reported in Iran, where adult women who had a university education degree were more likely to adopt a healthy eating pattern ${ }^{(36)}$. This could be explained by the fact that education enables people to obtain information about health, especially nutrition-related information, and consequently contributes to improving behaviour and eating habits.

The relationship between dietary patterns and lifestyle characteristics found in the present study supports the theory that food choices are part of a larger pattern of health-related characteristics and behaviours ${ }^{(42,43)}$. The concept of a 'prudent diet' could be extended to a 'prudent profile' that includes breakfast consumption, no smoking and less eating while watching TV, in addition to higher education. Our findings indicate a positive association of the traditional Lebanese and prudent patterns with the frequency of breakfast consumption. In fact, regular breakfast consumption has been consistently reported to be associated with better eating habits and lower levels of overweight and obesity ${ }^{(44-4)}$. In addition, the results of the present study revealed that the Western and prudent patterns were strongly associated with eating while watching TV. Specifically, a positive association with the former and a negative association with the latter were noted. These findings are in accordance with the results of previously published studies, in which an unhealthy dietary pattern behaviour was found to be associated with an overall unhealthy lifestyle ${ }^{(47,48)}$. These associations could be due to the fact that it is more common to eat sweets, desserts, salty 
snacks or ice cream while watching TV and due to the vast array of fast-food advertisements to which individuals are exposed while watching $\mathrm{TV}^{(49-51)}$.

Our hypothesis that the Western dietary pattern is associated with obesity was confirmed by the significant associations with BMI and WC, even after adjustment for sociodemographic factors and energy intake. This finding is consistent with a body of literature that showed that the Western pattern is associated with an increased risk of obesity, including a high BMI and elevated $\mathrm{WC}^{(27,52-54)}$. This result reinforces the importance of Westernization and nutritional transition in the alarmingly increasing prevalence of obesity in developing countries. The Lebanese traditional pattern that we defined in the present study was not consistently associated with BMI. This finding is similar to another study conducted in the region, where the Iranian traditional diet was also not found to be associated with obesity ${ }^{(53)}$. The complex nature of these traditional patterns makes interpretation very difficult. The Lebanese diet, as defined in our findings, is highly loaded on fruit and vegetables. With these elements, a negative association between this dietary pattern and risk of obesity is expected. However, some energy-dense foods such as whole-dairy products and refined grains were also heavily consumed in this dietary pattern and may have counteracted the positive effects that the intake of fruit and vegetables might have had on obesity.

The strengths of our study include the extensive information on lifestyle and meal patterns, the large sample size, the national representation of the studied population and the objective method adopted to record height and weight. Some limitations should be considered when interpreting the findings of the present study. First, factor analysis is a data-driven method and tends to define population-specific patterns. Hence, our results are likely to represent patterns that are, in some aspects, specific to the Lebanese population. Second, this is a cross-sectional study and its findings can mainly be used to test associations rather than to assess causal relationships. Hence, it remains unclear from the results of the present study whether individuals who adhere to a Western type of diet have a higher BMI or those with a higher BMI tend to eat unhealthy food. In addition, limitations of the use of the FFQ for dietary assessment, such as measurement errors, reliance on memory, the limited number of food items included in the food list and the high proportion of low-energy reporters, should be taken into account ${ }^{(55)}$. Nevertheless, studies have shown that the FFQ remains the most suitable dietary data collection tool in large epidemiological studies as it provides information on an individual's habitual diet over longer periods of time and allows ranking of individuals according to food or nutrient intakes ${ }^{(4,56)}$. It is important to note that the FFQ used in the present study was not validated in our study population; however, in another study investigating dietary patterns and metabolic syndrome among
Lebanese men using the same FFQ, significant correlations were found between dietary cholesterol intake and plasma total and LDL cholesterol levels (Pearson's correlation $r^{2}=0.3$ and 0.2 for total and LDL cholesterol, respectively; F Naja and L Nasreddine, unpublished results). The FFQ used in the present study was administered by a trained dietitian and was not self-completed. This offers many advantages in that the self-administered FFQ requires a literate population and may also result in inconsistent interpretations and lower than desired response and completion rates, each of which may compromise the validity of the data ${ }^{(57)}$. Finally, the use of factor analysis requires several arbitrary assumptions related to the selection of food groupings, the number of retained factors and their labels ${ }^{(3,11,58)}$. Nevertheless, to minimize subjectivity, the food groupings used in the present study were similar to those reported by others ${ }^{(27,35,59)}$ and the selection of factors was carried out after evaluating the scree plots and eigenvalues.

In conclusion, the present study provides a better understanding of the nutritional intake of the Lebanese population. It identified four dietary patterns: Western, traditional, prudent, and fish and alcohol, with age, sex, education, income and meal patterns shown to be significantly associated with the adoption of these patterns. Only the Western pattern was associated with higher BMI and WC. These findings lay the grounds for future interventions targeted at reducing rates of overweight and obesity, which have lately been shown to be on the rise in the country ( $\mathrm{N}$ Hwalla, unpublished results). The observed association between the Western pattern, BMI and WC justifies interventions: first, to discourage the intake of fast food and other energy-dense foods such as pies and pizzas, fried potatoes and sweets; and second, to promote the consumption of the traditional Lebanese diet based on fruit and vegetables.

\section{Acknowledgements}

The present study was funded by the Center for Disease Control, WHO and the Lebanese National Council for Scientific Research. The authors have no conflict of interest to declare. N.F. and N.L. wrote the paper; H.N. and A.M.S. designed and supervised the study and critically reviewed the paper; M.C.C. conducted the dietary survey; L.I. calculated nutritional intakes; N.F., N.L., N.A. and L.I. performed data analysis; N.F. and N.L. contributed equally to this manuscript. All authors contributed to writing the paper and discussed the results.

\section{References}

1. Yach D, Hawkes C, Gould CL et al. (2004) The global burden of chronic diseases: overcoming impediments to prevention and control. JAMA 291, 2616-2622. 
2. Boeing H, Wahrendorf J \& Becker N (1999) EPIC-Germany: a source for studies into diet and risk of chronic diseases. European Investigation into Cancer and Nutrition. Ann Nutr Metab 43, 195-204.

3. Hu FB (2002) Dietary pattern analysis: a new direction in nutritional epidemiology. Curr Opin Lipidol 13, 3-9.

4. Hu FB, Rimm E, Smith-Warner SA et al. (1999) Reproducibility and validity of dietary patterns assessed with a foodfrequency questionnaire. Am J Clin Nutr 69, 243-249.

5. Hu FB, Rimm EB, Stampfer MJ et al. (2000) Prospective study of major dietary patterns and risk of coronary heart disease in men. Am J Clin Nutr 72, 912-921.

6. Jacques PF \& Tucker KL (2001) Are dietary patterns useful for understanding the role of diet in chronic disease? $\mathrm{Am} \mathrm{J}$ Clin Nutr 73, 1-2.

7. Slattery ML (2008) Defining dietary consumption: is the sum greater than its parts? Am J Clin Nutr 88, 14-15.

8. Fung TT, Willett WC, Stampfer MJ et al. (2001) Dietary patterns and the risk of coronary heart disease in women. Arch Intern Med 161, 1857-1862.

9. Fung TT, Stampfer MJ, Manson JE et al. (2004) Prospective study of major dietary patterns and stroke risk in women. Stroke 35, 2014-2019.

10. Lutsey PL, Steffen LM \& Stevens J (2008) Dietary intake and the development of the metabolic syndrome: the Atherosclerosis Risk in Communities Study. Circulation 117, 754-761.

11. Newby PK, Muller D, Hallfrisch J et al. (2004) Food patterns measured by factor analysis and anthropometric changes in adults. Am J Clin Nutr 80, 504-513.

12. Handa K \& Kreiger N (2002) Diet patterns and the risk of renal cell carcinoma. Public Health Nutr 5, 757-767.

13. Kant AK (2004) Dietary patterns and health outcomes. J Am Diet Assoc 104, 615-635.

14. Williams DE, Prevost AT, Whichelow MJ et al. (2000) A cross-sectional study of dietary patterns with glucose intolerance and other features of the metabolic syndrome. Br J Nutr 83, 257-266.

15. Panagiotakos DB, Pitsavos C, Skoumas Y et al. (2007) The association between food patterns and the metabolic syndrome using principal components analysis: The ATTICA Study. J Am Diet Assoc 107, 979-987.

16. Van Dam RM, Rimm EB, Willett WC et al. (2002) Dietary patterns and risk for type 2 diabetes mellitus in US men. Ann Intern Med 136, 201-209.

17. Fung TT, Willett WC, Stampfer MJ et al. (2001) Dietary patterns and the risk of coronary heart disease in women. Arch Intern Med 161, 1857-1862.

18. Jacques PF \& Tucker KL (2001) Are dietary patterns useful for understanding the role of diet in chronic disease? $A m \mathrm{~J}$ Clin Nutr 73, 1-2.

19. Nishida C, Uauy R, Kumanyika S et al. (2004) The joint WHO/FAO expert consultation on diet, nutrition and the prevention of chronic diseases: process, product and policy implications. Public Health Nutr 7, 245-250.

20. de Oliveira MC, Sichieri R \& Venturim Mozzer R (2008) A low-energy-dense diet adding fruit reduces weight and energy intake in women. Appetite 51, 291-295.

21. Ello-Martin JA, Roe LS, Ledikwe JH et al. (2007) Dietary energy density in the treatment of obesity: a year-long trial comparing 2 weight-loss diets. Am J Clin Nutr 85, 465-1477.

22. Central Administration of Statistics (2004) The National Survey of Household Living Conditions. Beirut: CAS

23. IPAQ Research Committee (2005) Guidelines for Data Processing and Analysis of the International Physical Activity Questionnaire (IPAQ) - Short and Long Forms.

24. Michels KB \& Schulze MB (2005) Can dietary patterns help us detect diet-disease associations? Nutr Res Rev 18, 241-248.
25. Kerver JM, Yang EJ, Bianchi L et al. (2003) Dietary patterns associated with risk factors for cardiovascular disease in healthy US adults. Am J Clin Nutr 78, 1103-1110.

26. Paradis AM, Godin G, Perusse L et al. (2009) Associations between dietary patterns and obesity phenotypes. Int $J$ Obes (Lond) 33, 1419-1426.

27. Terry P, Hu FB, Hansen $\mathrm{H}$ et al. (2001) Prospective study of major dietary patterns and colorectal cancer risk in women. Am J Epidemiol 154, 1143-1149.

28. Paradis AM, Perusse L \& Vohl MC (2006) Dietary patterns and associated lifestyles in individuals with and without familial history of obesity: a cross-sectional study. Int $J$ Behav Nutr Phys Act 3, 38.

29. Tucker KL (2010) Dietary patterns, approaches, and multicultural perspective. Appl Physiol Nutr Metab 35, 211-218.

30. Newby PK, Muller D \& Tucker KL (2004) Associations of empirically derived eating patterns with plasma lipid biomarkers: a comparison of factor and cluster analysis methods. Am J Clin Nutr 80, 759-767.

31. Maskarinec G, Novotny R \& Tasaki K (2000) Dietary patterns are associated with body mass index in multiethnic women. J Nutr 130, 3068-3072.

32. Yang EJ, Kerver JM \& Song WO (2005) Dietary patterns of Korean Americans described by factor analysis. $\mathrm{J} \mathrm{Am} \mathrm{Coll}$ Nutr 2, 115-121.

33. Esmaillzadeh A \& Azadbakht L (2008) Food intake patterns may explain the high prevalence of cardiovascular risk factors among Iranian women. J Nutr 138, $1469-1475$.

34. Esmaillzadeh A \& Azadbakht L (2008) Major dietary patterns in relation to general obesity and central adiposity among Iranian women. J Nutr 138, 358-363.

35. Slattery ML (2010) Analysis of dietary patterns in epidemiological research. Appl Physiol Nutr Metab 35, 207-210.

36. Rezazadeh A, Rashidkhani B \& Omidvar N (2010) Association of major dietary patterns with socioeconomic and lifestyle factors of adult women living in Tehran, Iran. Nutrition 26, 337-341

37. Park SY, Murphy SP, Wilkens LR et al. (2005) Dietary patterns using the Food Guide Pyramid groups are associated with sociodemographic and lifestyle factors: the multiethnic cohort study. J Nutr 135, 843-849.

38. Sanchez-Villegas A, Delgado-Rodriguez M, MartinezGonzalez MA et al. (2003) Gender, age, socio-demographic and lifestyle factors associated with major dietary patterns in the Spanish Project SUN (Seguimiento Universidad de Navarra). Eur J Clin Nutr 57, 285-292.

39. Fung TT, Schulze M, Manson JE et al. (2004) Dietary patterns, meat intake, and the risk of type 2 diabetes in women. Arch Intern Med 164, 2235-2240.

40. Villegas R, Salim A, Collins MM et al. (2004) Dietary patterns in middle-aged Irish men and women defined by cluster analysis. Public Health Nutr 7, 1017-1024.

41. Winkvist A, Hornell A, Hallmans G et al. (2009) More distinct food intake patterns among women than men in northern Sweden: a population-based survey. Nutr J 19, 8-12.

42. Randall E, Marshall JR, Graham S et al. (1991) High-risk health behaviors associated with various dietary patterns. Nutr Cancer 16, 135-151.

43. Perrin AE, Dallongeville J, Ducimetiere P et al. (2005) Interactions between traditional regional determinants and socio-economic status on dietary patterns in a sample of French men. BrJ Nutr 93, 109-114.

44. Veltsista A, Laitinen J, Sovio U et al. (2010) Relationship between eating behavior, breakfast consumption, and obesity among Finnish and Greek adolescents. J Nut Educ Behav 42, 417-421.

45. Kent LM \& Worsley A (2010) Breakfast size is related to body mass index for men, but not women. Nutr Res 30, 240-245. 
46. Szajewska H \& Ruszczynski M (2010) Systematic review demonstrating that breakfast consumption influences body weight outcomes in children and adolescents in Europe. Crit Rev Food Sci Nutr 50, 113-119.

47. Kourlaba G, Panagiotakos DB, Mihas K et al. (2009) Dietary patterns in relation to socio-economic and lifestyle characteristics among Greek adolescents: a multivariate analysis. Public Health Nutr 12, 1366-1372.

48. Vereecken CA \& Maes L (2006) Television viewing and food consumption in Flemish adolescents in Belgium. Soz Praventivmed 51, 311-317.

49. Harris JL \& Bargh JA (2009) Television viewing and unhealthy diet: implications for children and media interventions. Health Commun 24, 660-673.

50. Custers K \& Van den Bulck J (2010) Television viewing, computer game play and book reading during meals are predictors of meal skipping in a cross-sectional sample of 12-, 14- and 16-year-olds. Public Health Nutr 13, 537-543.

51. Zimmerman FJ \& Bell JF (2010) Associations of television content type and obesity in children. Am J Public Health 100, 334-340.

52. Langsetmo L, Poliquin S, Hanley DA et al. (2010) Dietary patterns in Canadian men and women ages 25 and older: relationship to demographics, body mass index, and bone mineral density. BMC Musculoskelet Disord 11, 20.
53. Esmaillzadeh A, Kimiagar M, Mehrabi Y et al. (2007) Dietary patterns, insulin resistance, and prevalence of the metabolic syndrome in women. Am J Clin Nutr 85, 910-918.

54. Cunha DB, de Almeida RM, Sichieri R et al. (2010) Association of dietary patterns with BMI and waist circumference in a low-income neighbourhood in Brazil. BrJ Nutr 27, 1-6.

55. Willett W (1998) Nutrition Epidemiology, 2nd ed. New York: Oxford University Press.

56. Khani BR, Ye W, Terry P et al. (2004) Reproducibility and validity of major dietary patterns among Swedish women assessed with a food-frequency questionnaire. J Nutr 134, 1541-1545.

57. Caan BJ, Lanza E, Schatzkin A et al. (1999) Does nutritionist review of a self-administered food frequency questionnaire improve data quality? Public Health Nutr 2, 565-569.

58. Martinez ME, Marshall JR \& Sechrest L (1998) Invited commentary: factor analysis and the search for objectivity. Am J Epidemiol 148, 17-19.

59. Schulze MB, Hoffmann K, Kroke A et al. (2001) Dietary patterns and their association with food and nutrient intake in the European Prospective Investigation into Cancer and Nutrition (EPIC)-Potsdam study. Br J Nutr $\mathbf{8 5}$, $363-373$.

\section{Appendix}

\section{Food groupings based on culinary usage and nutrient content}

\begin{tabular}{|c|c|}
\hline Food group & Components \\
\hline Alcoholic beverages & Non-wine alcoholic beverages, beer, wine \\
\hline Whole bread & Whole-wheat bread \\
\hline Breakfast cereals & Regular corn flakes \\
\hline Burghul & Crushed parboiled wheat \\
\hline Coffee & Turkish coffee \\
\hline Cured meat & Luncheon, sausages, offals \\
\hline Low-fat dairy products & Half-skimmed milk, low-fat cheese, low-fat yoghurt \\
\hline Whole-dairy products & Whole milk, regular cheese, labneh, regular yoghurt \\
\hline Dried fruits & Raisin, prunes, etc. \\
\hline Eggs & Eggs boiled and fried \\
\hline Fast-food sandwiches & Shawarma sandwiches, falafel sandwiches, hamburger \\
\hline Fats and oils & Butter, ghee, vegetable oil \\
\hline Fish & Fried and broiled fish \\
\hline Fried potato & Potato fried, potato chips \\
\hline Fruits & Deep-yellow orange fruits, bananas, apples, strawberries, citrus fruits, grapes, fresh fruit juices \\
\hline Bottled fruit juices & All types of sweetened and bottled fruit juices \\
\hline Hot drinks & Cocoa, Nescafe, tea \\
\hline Ice cream & All types of ice cream, traditional and packaged \\
\hline Legumes & Beans, lentils, chickpeas, fava beans \\
\hline Mayonnaise & All types mayonnaise, salad dressing \\
\hline Meat and poultry & All types of red meat and poultry, cooked, fried or boiled \\
\hline Nuts and seeds & Nuts and seeds salted and roasted \\
\hline Olives & All types of pickled olives \\
\hline Pizzas and pies & Pizza, manaeesh cheese, manaeesh thyme, manaeesh kishk (kishk is a traditional yoghurt-based product) \\
\hline Refined grains & White bread, rice and rice products, cooked pasta \\
\hline Light soda & All kinds of sugar-free carbonated beverages \\
\hline Soda regular & Sugar-sweetened carbonated beverages \\
\hline Starchy vegetables & Potato, corn and peas \\
\hline Sweets & Cakes, cookies, doughnuts, muffins, Arabic sweets, honey, jam, sugar, chocolate \\
\hline Vegetables & Dark-green yellow vegetables, tomato, salad season, courgette, aubergine, cauliflower \\
\hline
\end{tabular}

